\title{
Surface physicochemical properties of semi-anthracitic coal from Painan-Sumatra during air oxidation
}

\author{
Anggoro Tri Mursito ${ }^{1}$ Tsuyoshi Hirajima ${ }^{2} \cdot$ Lina Nur Listiyowati ${ }^{1}$. \\ Sudarsono Sudarsono ${ }^{1}$
}

Received: 3 January 2018/Revised: 20 March 2018/ Accepted: 31 May 2018/Published online: 28 June 2018

(C) The Author(s) 2018

\begin{abstract}
Painan coals of West Sumatra were selected as semi-anthracitic coal sample for studying the physicochemical properties such as measurement, evaluation and description of the changes of surface characteristic of coal sample and their oxidation in the atmospheric air at a temperature ranging from 105 to $400{ }^{\circ} \mathrm{C}$ for $30 \mathrm{~min}$. Several methods are adopted to analyze and discuss several phenomena of the oxidized Painan coal surface during oxidation process for the change in the physicochemical properties as determined by Atomic Force Microscope (AFM), contact angle, Fourier Transform Infrared Spectroscopy (FTIR), Thermogravimetric and Differential Thermal Analysis (TG-DTA) analyses as well as other supporting analytical equipment. AFM analyses revealed some changes in adhesion force and surface morphology with more adhesion force available between 0.6 and $8.6 \mathrm{nN}$ on polished coal surfaces due to the increased oxidation temperature. The study revealed that the extent of hydrophobicity of coal surface decreased with the increased of oxidation temperature expressed as contact angles at about $80^{\circ}$ and $20^{\circ}$. Another phenomenon occurred during the experiment was hydrophilicity index of coal surface increase at approximately 1.3 and 2.9. Oxidation of coal that occurred with increased temperature also indicated an increase in oxygen content from 3.8\% to $22.9 \mathrm{wt} \%$. Increased oxygen functional group also noted that oxidation of coal took place during the treatment. We also found that oxidation treatment also affected the combustion properties of coal: decreasing ignition temperature between 452.9 and 317.6, lowering the reactivity of coal at maximum combustion rate temperature, and reflecting their char characteristics as burnt out, ranging from 652.3 to $648.5{ }^{\circ} \mathrm{C}$.
\end{abstract}

Keywords Coal surface $\cdot$ Adhesion force $\cdot$ Contact angle $\cdot$ Combustion properties

\section{Introduction}

Understanding of coal surface physic and chemical properties is the prerequisite to better know the unique characteristic of coal that is easily affected by the oxidation process. A conventional method of characterizing

Anggoro Tri Mursito

anggoro@geotek.lipi.go.id; anggorotrim@yahoo.com

1 Research Centre for Geotechnology, Indonesian Institute of Sciences (LIPI), Jl. Sangkuriang Komplek LIPI, Gd. 70, Bandung 40135, Indonesia

2 Department of Earth Resources Engineering, Faculty of Engineering, Kyushu University, 744 Motooka, Nishiku, Fukuoka 819-0395, Japan microscale coal surface properties is by using images microscopy such as scanning electron microscopy and transmitting electron microscopy. Several electron microscopy methods are limited to understanding the adhesion force characteristics that serve as an indirect way to determine coal surface morphology and its structure.

AFM is one of the available tools for measuring the surface physical properties with various applications such in material sciences and mineral engineering (O'Brien and Hermann 1973; Fuji et al. 1999; Karoussi et al. 2000; Sedin and Rowlen 2000; Jones et al. 2002; Farquhar et al. 2003; Leite et al. 2003; Butt et al. 2005; Das et al. 2010; Petrus et al. 2011). The method has an advantage of having simple sampling procedures, very high-resolution imaging and involving quantitative analyses. An early application of AFM technique on coal observed the surface topography 
and characteristics of the coal pore structure (Yumura et al. 1993). Even though the observing range and area of AFM is limited, its wide range of applications on coal pore sciences and physical structure has been well studied (Yordan and Yoon 1988; Drelich et al. 1997; Lawrie et al. 1997; Cohen et al. 1998; Datta et al. 2000; Bruening and Cohen 2005; Ozdemir et al. 2009; Liu et al. 2010; Morga 2011; Wu et al. 2014; Xia and Xie 2014; Xia and Yang 2014; Pan et al. 2015). AFM images could support some evidence for the presence of the porosity in coal observed for both the vitrinites and inertinites (Lawrie et al. 1997). At early stage artificially peat coalification, AFM is used for surface roughness characterization at micrometer scale (Cohen et al. 1998). Coking coal structural alteration was resulting from heat treatment at $400-1200{ }^{\circ} \mathrm{C}$ could change surface roughness of semifusinite and fusinite (Morga 2011). The coal sample after oxidation using $\mathrm{H}_{2} \mathrm{O}_{2}$, AFM images show more area of lower topography (resulting from loss of material) (Bruening and Cohen 2005). A recent report on nanometer scale AFM images of anthracite as results of the differences in the degree of metamorphism, the macromolecular polymerization is enhanced, and micropores are predominant (Pan et al. 2015). Using the method and results described by the previous researchers, AFM can provide significant information relative to physical properties of coal surface. However, the last results did not report adhesion force phenomenon resulting from coal surface during oxidation as valuable information for further study of coal surface contact angle and its chemical properties.

The use of FTIR in the study of coal functional groups change during oxidation and weathering process has also recently attracted more attention (Liotta et al. 1983; Rhoads et al. 1983; Gethner 1985; Yürüm and Altuntas 1998; Wang et al. 2010). Typically, the chemical structure of coal changes with increased oxidation temperature process, while the functional groups show differences. Depending on the oxidation temperatures, there was different relative proportions increase in carbonyl and carboxyl groups (Rhoads et al. 1983). Oxidation of coal can also lead to the formation of new carbonyl species (Gethner 1985). Coal is complex, predominantly organic-containing porous solid which is important both as an energy and as a chemical source material. The physical and chemical properties of most coals are extremely sensitive to air oxidation and their mechanism studied by In Situ FTIR Difference Spectroscopy technique (Gethner 1987). Investigations of the different air oxidation temperature, the absorption in the aliphatic $\mathrm{C}-\mathrm{H}$ stretching region decreased, while the absorption in the $\mathrm{C}=\mathrm{O}$ stretching region presented a significant increase (Yürüm and Altuntas 1998). The chemical structure of coal is extremely complex, and at the initial stage of coal, oxidation shows the increase of oxygen-containing groups and reduction of aliphatic groups in the FTIR spectrograms (Wang et al. 2010). Therefore, understanding oxygen functional groups changes in coal structure also infer changes in the physicochemical properties of coal surface.

Other phenomena of coal oxidation process that will be addressed in this study are the effects of hydrophobicity and hygroscopic properties on coal surface, contact angle and coal combustion properties. Contact angle has been used to analyze and evaluate the hydrophobic nature of coal, first by Brady and Gauger (1940), Horsley and Smith (1951), Sun (1954), Apian (1983) who showed that the hydrophobicity varied with rank; the relationship between the contact angle and rank as well as relating the contact angle to coal floatability. The reaction of oxygen in the presence of water and constant relative humidity possibly takes place on the oxidized coal surface. Weathering process of anthracite coal could produce more hydrophilic surface and not only changed the surface chemical properties of anthracite coal, but also changed the surface morphology of anthracite coal (Xia and Yang 2014). The contact angles of anthracite coals, when heated at the hightemperature process of $600{ }^{\circ} \mathrm{C}$, decrease quickly with the increase of contact time (Xia and Xie 2014). The water is advancing, and receding contact angles were measured on coal surfaces by varying the bubble size, using the captivebubble technique (Drelich et al. 1997). The TGA, DTG and DTA curves provided parameters which characterize the tendency of a given coal towards oxidation. Several parameters can also be used to approximate the specific active surface area of coal in reaction with oxygen due to the negative effects of coal oxidation, such as self-oxidation, and tested by analysis of the above specified thermoanalytical curves by TGA (Matyjaszczyk and Przeliorz 1985). Vaporization of moisture on coal surface was express for the endothermic reaction at around $60{ }^{\circ} \mathrm{C}$ shown by DTA data (Umar et al. 2005). The exotherm increases with increasing of low-temperature oxidation and is most pronounced for the coal most prone to spontaneous combustion (Clemens et al. 1990). The correlation of contact angle and hydrophilicity index is also studied. In this paper, we discuss the character change by using drop master contact angle and TG-DTA.

The aim of the present work is to measure, evaluate and describe changes of surface characteristic of coal sample during the oxidation treatment in the atmospheric air at $105-400{ }^{\circ} \mathrm{C}$, and to obtain a better understanding of the relationship between changes in oxygen-containing carbon functional groups and the order of related hydrophobicity of contact angle, adhesion force and hygroscopic properties of coal surface to the combustion characteristic. 


\section{Experimental}

\subsection{Geological setting and material, apparatus and experimental procedure}

The coal sample obtained from Painan area in West Sumatra, Indonesia was classified as semi-anthracite to anthracite. The investigated area is tectonically included in the forearc basin as shown in Fig. 1. The coal-bearing Painan Formation was deposited during the Oligo-Miocene. It consists of breccia, sandstone, claystone, black silt, coaly shale, clayey sand, sandy clay, and conglomerate. This area is commonly covered by sedimentary rock including one shale and carbonaceous shales with thin coal intercalation; laterally and limited distribution and locally lenses and mostly affected by normal faults and also strikeslip faults.

Regionally, the primary fault affecting this area is the Sumatran fault which is heading to the sliding faults and normal faults, trending northwest-southeast. In this area, the coals were also locally intruded by granitic sills. The Painan area is situated in a tectonically active region. The coal-bearing strata were subjected to at least one period of folding and faulting and later affected by extrusive and intrusive magmatic activity.

Coals from this area are premium ones, which have been used for metallurgical coking coal and as a blending coal material. Typically, this kind of coal contained high fixed carbon of $92.3 \mathrm{wt} \%$, the energy content of $8294 \mathrm{kcal} / \mathrm{kg}$ and very low ash content of $1.6 \mathrm{wt} \%$ as well as sulfur contents of $0.6 \mathrm{wt} \%$. Selection of low oxygen content of coal is suitable for studying the oxidation process at elevated temperature. The typical properties of semi-anthracitic coal from the study site are described in Tables 1 and 2 .

A diamond saw cut selected coal sample grains of about $5 \mathrm{~cm}^{2}$ area and they were given rough to fine wet polish on a series of abrasive papers on slow speed $\left(35 \mathrm{rev} \mathrm{min}^{-1}\right)$, rotating laps using 220, 400, 800, 1500, 2000 mesh and $1200 /$ JIS $4000 \mathrm{Si}-\mathrm{C}$ (Maruto). The samples were then washed vigorously to remove any adhering coal and $\mathrm{Si}-\mathrm{C}$ particles and two final dry polishes on DP-Mol and DP-Nap (Struers), sprayed gently by $\mathrm{N}_{2}$ gas and stored inside the desiccators and maintained in dry conditions. Oxidation experiments were conducted in a conventional oven and furnace simultaneously (Eyela WFO-500 and TMF-2200)

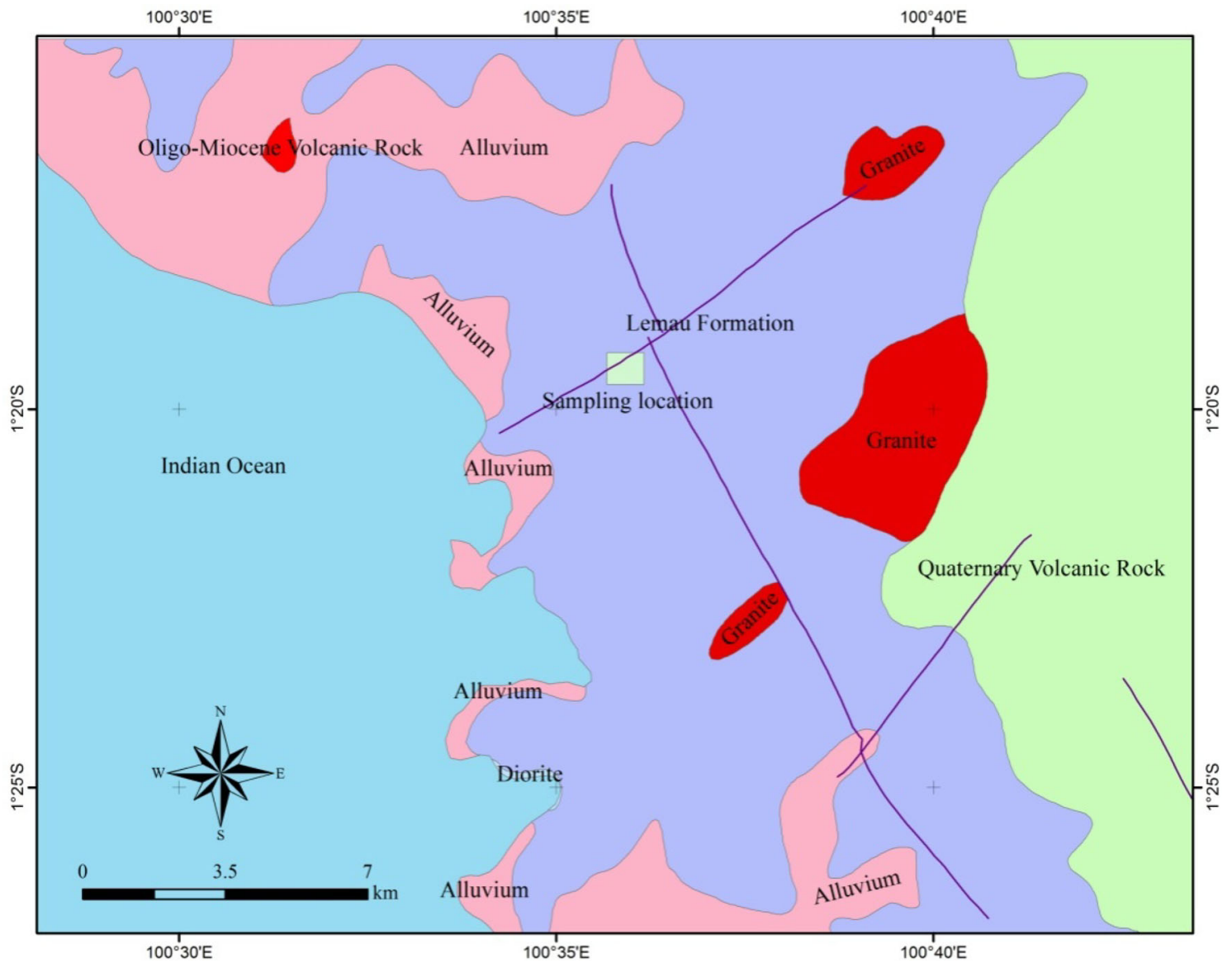

Fig. 1 Geological map of Painan area (modified from (Rosidi et al. 1996) and the location of the main coal fields 
Table 1 Proximate analysis and calorific value of Painan coal

\begin{tabular}{ll}
\hline Properties & Raw \\
\hline Proximate analysis (wt\%) & \\
Inherent Moisture (a.d.b) & 1.4 \\
Total Moisture (a.d.b) & 2.2 \\
Volatile Matter (d.a.f) & 7.7 \\
Fixed Carbon (d.a.f) & 92.3 \\
Ash (d.b) & 1.6 \\
Calorific value (CV) (kcal/kg) (d.a.f) & 8294 \\
\hline
\end{tabular}

d.b dry basis, a.d.b air dry basis, d.a.f dry ash free basis

Table 2 Ultimate analysis of Painan coal and oxidized coal

\begin{tabular}{|c|c|c|c|c|c|c|}
\hline \multirow[t]{2}{*}{ Properties } & \multirow[t]{2}{*}{ Raw } & \multicolumn{5}{|c|}{ Treated temperatures $\left({ }^{\circ} \mathrm{C}\right)$} \\
\hline & & 105 & 200 & 250 & 300 & 400 \\
\hline \multicolumn{7}{|c|}{ Ultimate analysis (wt\%) (d.a.f) } \\
\hline$C$ & 90.7 & 90.3 & 90.4 & 89.1 & 87.1 & 72.4 \\
\hline$H$ & 3.2 & 3.2 & 3.1 & 2.9 & 2.9 & 2.3 \\
\hline$N$ & 1.7 & 1.7 & 1.7 & 1.6 & 1.6 & 1.7 \\
\hline $\mathrm{O}$ (diff.) & 3.8 & 4.2 & 4.2 & 5.8 & 7.8 & 22.9 \\
\hline$S$ & 0.6 & 0.6 & 0.6 & 0.6 & 0.6 & 0.6 \\
\hline
\end{tabular}

d.a.f dry ash free basis, diff. differences

in the atmospheric forced convection air flow system at 105 to $400{ }^{\circ} \mathrm{C}$ for $30 \mathrm{~min}$.

\subsection{Analysis}

A vitrinite reflectance measurement was performed by Carl Zeiss microscope, Axioimager A1 m model. Reflectance was measured on telinite using a $50 \times$ magnification objectives lens under oil immersion $\left(n=1.518\right.$ at $\left.23{ }^{\circ} \mathrm{C}\right)$. The vitrinite reflectance determination was obtained from at least 100 points according to AS 2856-3. Maceral analysis procedure was based on AS 2856-2 and conducted in reflected white light and fluorescence irradiated by blue light. Five hundred points were counted on each polished sample. Maceral classification groups were based on AS 2856.

AFM examination was carried out on a polished coal sample, using NanoNavi II (SII) atomic force microscope in the contact mode. All measurements were performed in atmospheric air at room temperature using rectangular micro silicon cantilevers of a nominal elastic constant of 0.02 and $0.08 \mathrm{~N} / \mathrm{m}$ and a typical resonance frequency of $10.9 \mathrm{kHz}$. Scanning mode measurement was used in 2 channels simultaneously with scanning speed of 0.35 and $1.00 \mathrm{~Hz}$ and force reference of $1.0 \mathrm{~nm}$ in a measurement area of $5 \mu \mathrm{m} \times 5 \mu \mathrm{m}$. Adhesion force analysis was employed using the Scanning Image Probe Processor SPIPTM 5.1.7 software (Petrus et al. 2011).

The water sessile drop contact angle measurement was identified using contact angle meter type drop master (Kyowa interFAce Measurement and Analysis System FAMAS) of a small drop of ultrapure water with the electrical resistivity of $18.2 \mathrm{M} \Omega \mathrm{cm}$ at $25{ }^{\circ} \mathrm{C}$. The freshly polished coal sample was quickly dried with $\mathrm{N}_{2}$ gas and immediately placed on the measuring place. A very few drops of ultrapure water of $0.2 \mu \mathrm{L}$ were deposited on the flat coal surface with a speed of $1000 \mathrm{~ms}$ for $10 \mathrm{~s}$ contact. The contact angle was measured for ten drops on the different polished coal surface and oxidized surface to ensure reproducibility.

The primary components and chemical structure of the coal were analyzed by FTIR using diffuse reflectance infrared Fourier transform spectroscopy (DRIFTS) and JASCO IR Mentor Pro 6.5 software for spectral analysis and other methods previously described by the authors and detailed operation, and band assignments can be found elsewhere (Mursito et al. 2010, 2011; Mursito and Hirajima 2012). A TG-DTA test was conducted using a TG-DTA analyzer (DTG-60 Bruker AXS) specifically for studying the combustible organic matter on coal surface at early stage. Briefly, the semi-anthracitic coal sample and treated coal was milled to less than $75 \mu \mathrm{m}$ and it passed through 200 mesh screens. Prior to the analysis, hygroscopy test was examined to have a constant humidity environment of a treated coal samples at about $90 \%$ humidity and room temperature. A $5 \mathrm{mg}$ sample was then placed in a platinum cell and subjected to an air flow rate at $25 \mathrm{~mL} / \mathrm{min}$ and a heating rate at $10{ }^{\circ} \mathrm{C} / \mathrm{min}$. The maximum experimental temperature was $800{ }^{\circ} \mathrm{C}$. A number of parameters were derived from the curves, which are defined by (Ma et al. 1989; Ohki et al. 1999; Mahidin et al. 2003; Umar et al. 2005), including the ignition temperature $\left(T_{\mathrm{ig}}\right)$, maximum combustion rate temperature $\left(T_{\max }\right)$, maximum combustion rate $\left(R_{\max }\right)$ and char burn-out temperature $\left(T_{\mathrm{bo}}\right)$.

\section{Results and discussion}

\subsection{Coal sample and products properties}

Based on $1.93 \%$ vitrinite reflectance, the rank of coal is classified as semi-anthracite. As described in Fig. 2, macerals were composed predominantly of vitrinite $95.1 \%$, while liptinite $2.35 \%$ and inertinite $1.71 \%$ group macerals were less abundant. Minerals were found in small amounts of $0.84 \%$, and most of them were pyrite and clay.

As expected, the oxygen content increased with the oxidation temperature. Table 2 shows that the chemical 

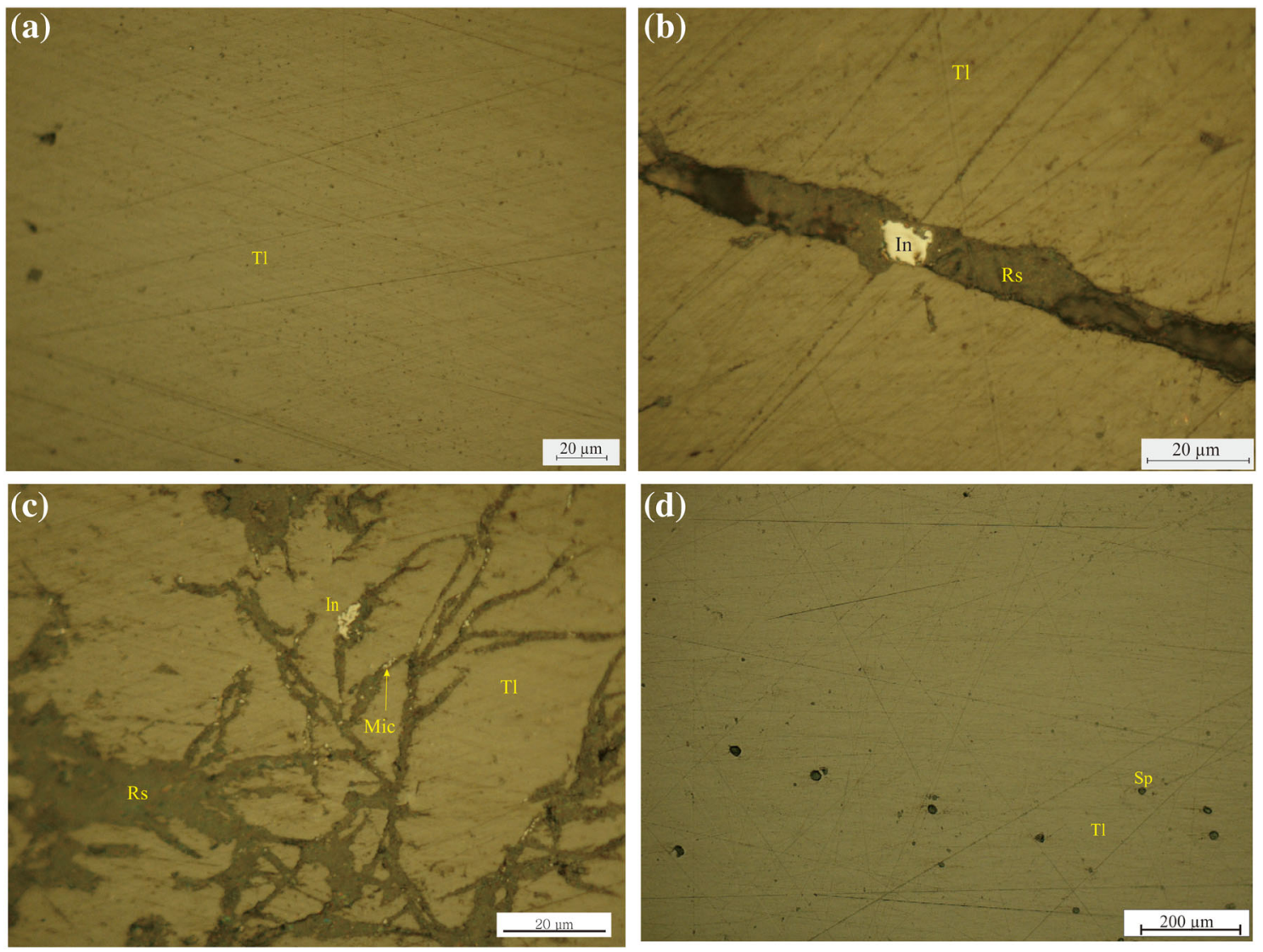

Fig. 2 Under reflecting light microscope, the polished coal samples showing a.telinite (Tl); $b$. telinite cross cutting by resinite (Rs) and inertodetrinite (In) veinlet; $c$. branching of veinlet compossed inertodetrinite, resinite and micrinite (Mic); $d$. diseminated of sporinite (Sp) within telinite

properties of oxidized coal were mainly affected by the oxidation temperature at $105-400{ }^{\circ} \mathrm{C}$. With the increase of temperature, significant increase in $\mathrm{O}$ and decrease $\mathrm{C}$ contents were observed in the studied coals. The increase of oxygen content in oxidized products revealed that the oxidation process took place directly in the coal sample. The apparent increase in the oxygen content shown in Table 2 is a measurement of total oxidation and should not be interpreted directly as an increase in oxygen functionality on particle surfaces. The oxygen content increased from $3.8 \%$ to $22.9 \mathrm{wt} \%$ and the oxidation process influenced the decreased carbon content from $90.7 \%$ to 72.4 wt $\%$. The variations of $\mathrm{H}$ and $\mathrm{N}$ contents in coals were insignificant. Carbon content was lost by approximately $20 \%$ in oxidized coal relative to semi-anthracitic coal sample at $400{ }^{\circ} \mathrm{C}$, which was possibly due to partial destruction and conversion of reactive materials into some oxidized components in the products into gaseous products $\left(\mathrm{CO}, \mathrm{CO}_{2}\right)$ and stable solid complexes (Wang et al. 2010). Air oxidation of the coal can result in the uptake of oxygen and the conversion of hydrocarbon constituents into oxygen-containing functional groups (Bouwman and Freriks 1980; Rhoads et al. 1983; Huffman et al. 1985).

\subsection{Atomic Force Microscope examination results}

Observations of coal surface morphology, force curve profile, and adhesion force are shown in Figs. 3, 4 and 5. A contact mode 2D image and 3D surface morphology revealed a change in a selection of evaluation of curving force due to the development of debris and spotted curved obtained in oxidized coal surface. Selection of the micro silicon cantilevers tip area on the oxidized coal surface at $400{ }^{\circ} \mathrm{C}$ increased the difficulty and resulted in a wide difference on the cantilever deflection as described in Fig. 4. An extremely small area of cantilevers tip measurement could give the most important information and the critical analysis of the adhesion force results. Once the tip is in contact with the oxidized coal surface, cantilever deflection will increase as the fixed end of the cantilever is brought closer to the sample. The increase in the oxidation temperature of coal, the wider the piezo displacement as well 

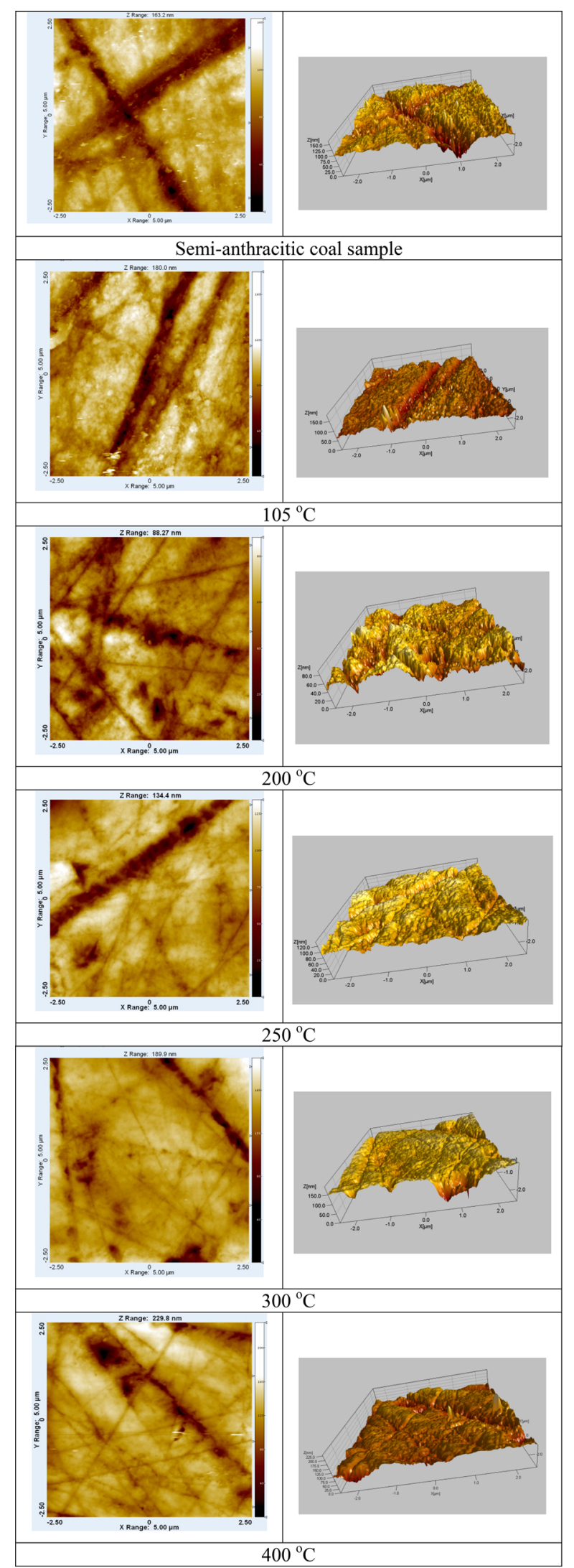

4Fig. 3 A contact mode of 2D AFM selected images and surface morphology of a coal surface as a function of oxidation treated temperature

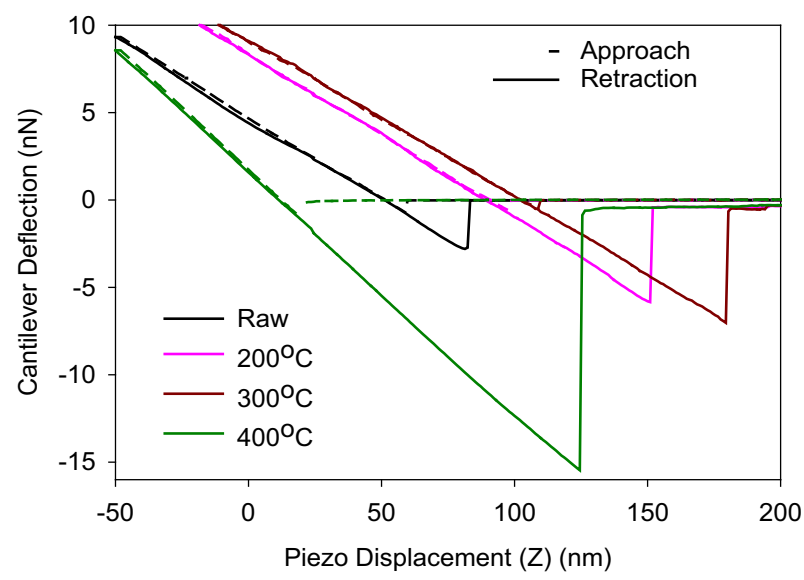

Fig. 4 Selected force curve profile of a coal surface as a function of oxidation treated temperature

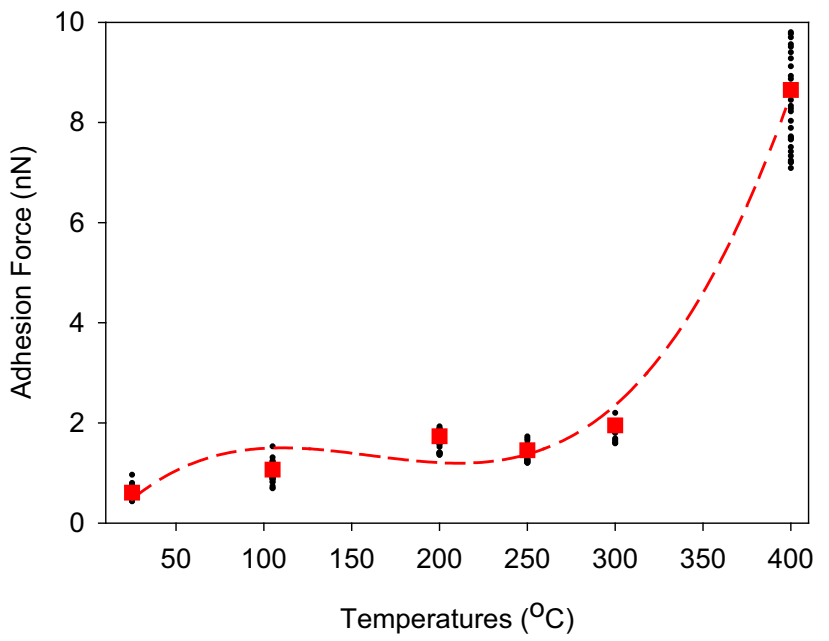

Fig. 5 Adhesion force $s$ as a function of oxidation treated temperature measured on 3-4 spots for 10 times examination

as, the deeper the deflected and retraction value were obtained from the cantilevers.

Another critical measurement of the AFM force curve is the point at which the adhesion is broken, and the cantilever deflects from the surface. Measuring the rupture force required breaking the bond or adhesion depends on the value of displacement and deflection of cantilevers. Figure 5 shows that oxidation temperature increases exponentially with the adhesion forces. Adhesion force at semi-anthracitic coal and oxidized coal at $400{ }^{\circ} \mathrm{C}$ was on average about $0.6-8.6 \mathrm{nN}$ respectively. A very slight decrease was observed at 200 and $250{ }^{\circ} \mathrm{C}$ while a sharp increase could be seen at $1.9-8.6 \mathrm{nN}$ when heated at 300 
and $400{ }^{\circ} \mathrm{C}$. The phenomenon of adhesion force under ambient conditions at semi-anthracitic coal arises because the formation of a water layer on the hydrophobic surface is insufficient and in comparison, to the oxidized coal at $400{ }^{\circ} \mathrm{C}$ would possibly more hydrophilic surface properties (Butt et al. 2005; Das et al. 2010).

\subsection{FTIR examination results}

FTIR spectrograms of the semi-anthracitic coal samples at different oxidation temperatures are shown in Fig. 6. The results showed the change of oxygen functional groups and absorption relative intensity of the FTIR spectrograms with an increase in oxidation temperature. The increase of oxidation temperature resulted in a significant increase in the concentration of oxygen-containing functional groups. Aromatic carbon remained relatively unchanged under the increasing of oxidation temperature conditions, while aliphatic hydrogen decreased significantly at higher temperature.

The aliphatic hydrocarbon absorbance decreased with the increase of oxidation temperature. Both the methylene unsymmetrical and symmetrical stretching vibrations peaking at 3040 and $2920 \mathrm{~cm}^{-1}$ relative intensity declined with the increase in oxidation temperature, which showed that the aliphatic hydrocarbon had the least difficulty in reacting with the absorbed oxygen. Since the oxidation temperature increased, the reaction of the side chains of aliphatic hydrocarbon with oxygen was difficult, resulting in unstable aliphatic hydrocarbon absorbance and producing carbonyl groups. The presence of a significant amount of active oxygen-containing functional groups led to increasing tendency of coal to further oxidation. Also, the higher level of the oxidation temperature is, the easier the re-oxidation occurs (Liang et al. 2015).

Significant changes in the oxygen content of the functional groups could also be observed in the 1900 and $1700 \mathrm{~cm}^{-1}$. The carboxyl was determined, and the spectrum of $1900 \mathrm{~cm}^{-1}$ at $400{ }^{\circ} \mathrm{C}$ was completely lost. The relative intensity of the carboxyl band $\mathrm{C}=\mathrm{O}$ groups at $1700 \mathrm{~cm}^{-1}$ started to develop at $300{ }^{\circ} \mathrm{C}$. The carboxyl band $\mathrm{C}=\mathrm{O}$ groups at $1590 \mathrm{~cm}^{-1}$ and aromatic ring $\mathrm{C}=\mathrm{C}$ stretch absorbance at $1420 \mathrm{~cm}^{-1}$ did not change much in the oxidation process. During operation, aromatic ring stretch absorption remained relatively unchanged up to $300{ }^{\circ} \mathrm{C}$ and decreased slightly after that because of some pyrolysis reactions that took place at higher temperatures (Tahmasebi et al. 2012). The carboxyl absorbance became apparent with the increased temperature, showing the gradual generation of carboxyl groups. The relative intensity of carboxyl absorbance at $1700 \mathrm{~cm}^{-1}$ was low at $300{ }^{\circ} \mathrm{C}$ and gradually increased at $400{ }^{\circ} \mathrm{C}$, probably due to the active carboxyl-containing groups, including aldehyde,

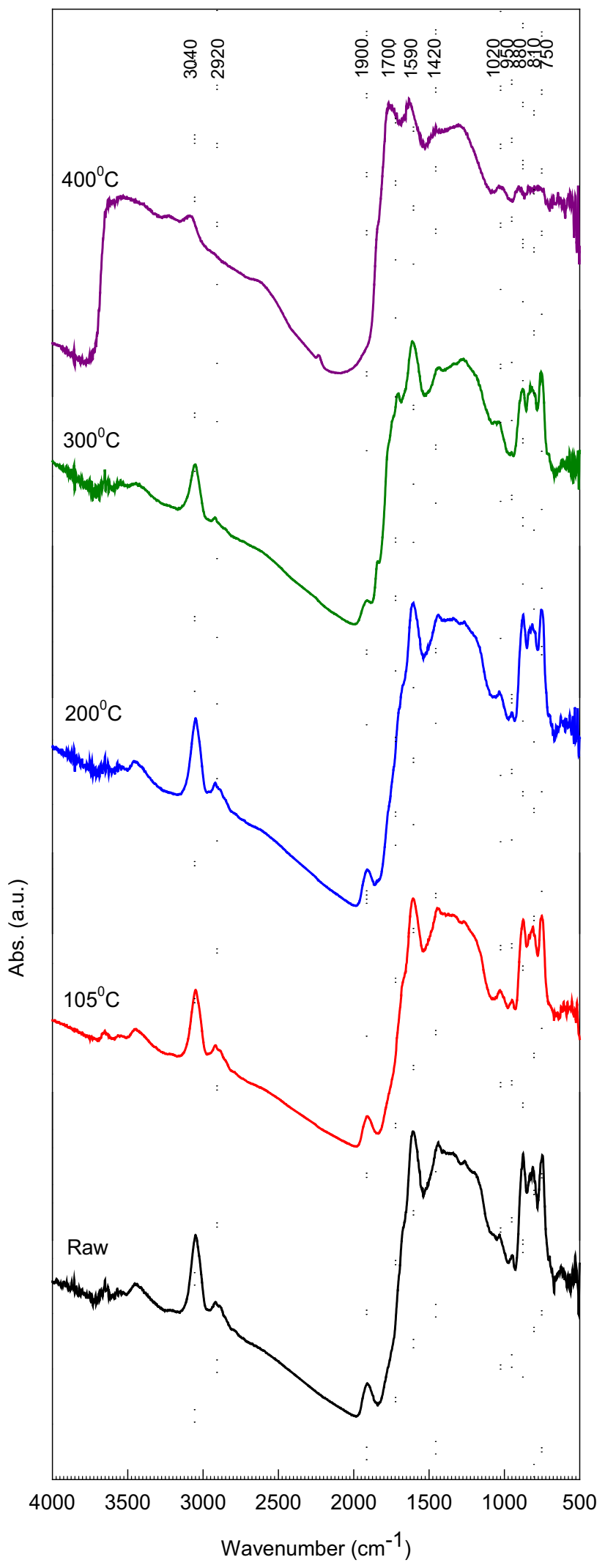

Fig. 6 Typical FTIR spectrogram of a semi-anthracitic coal sample and oxidized coal as a function of oxidation treated temperature 
ketone and acid, which were easy to transform and difficult to accumulate (Wang et al. 2010).

$\mathrm{C}-\mathrm{O}-\mathrm{R}$ structures of ethers were observed at $1020 \mathrm{~cm}^{-1}$ and they remained stable with the increase of oxidation temperature. The distribution of aromatic $\mathrm{C}-\mathrm{H}$ out of plane bending modes at $900-700 \mathrm{~cm}^{-1}$ was also observed during the oxidation process. Aromatic nuclei $\mathrm{CH}$ at $750-880 \mathrm{~cm}^{-1}$ tended to diminish sharply in its relative intensity at $400{ }^{\circ} \mathrm{C}$. The stability of the aromatic nucleus during the coal oxidation express the core aromatic nucleus in the structural unit basically did not participate in the oxidation reaction (Wang et al. 2010).

\subsection{Contact angle examination results}

The contact angles at selected different contact times and spots were obtained and shown in Fig. 7. As shown in Fig. 8, the contact angle decreased due to the increase temperature of oxidation processes. The average contact angle of fresh and semi-anthracitic coal was about $78.3{ }^{\circ} \mathrm{C}$, while the contact angle of oxidized coal decreased when heated only at about $26.8^{\circ}$ at $400{ }^{\circ} \mathrm{C}$ in the oxidation. It indicated that the sessile water droplet was averagely hydrophobic to spread on the fresh coal surface along with the increase of contact time. Hydrophobicity of deeper coal surface layer might be higher as undisturbed condition. Meanwhile, the oxidized coal surface became more hydrophilic and had lower contact angle after oxidation processes. The contact angle of oxidized coal decreased faster at $200^{\circ}$ to $400{ }^{\circ} \mathrm{C}$. At the contact angle of $300{ }^{\circ} \mathrm{C}$, oxidized coal decreased for about $23 \%$ at only $10 \mathrm{~s}$ of contact time and possibly decreased as the sessile water droplet adsorbed to the surface. However, the hydrophobicity of oxidized coal was obviously changed. Another phenomenon observed was the hydrophilicity index. Yordan et al. studied coal surface wettability and correlated very well with directly measured contact angles, and with the hydrophilicity index as obtained from the infrared measurements. This index is defined as follows:

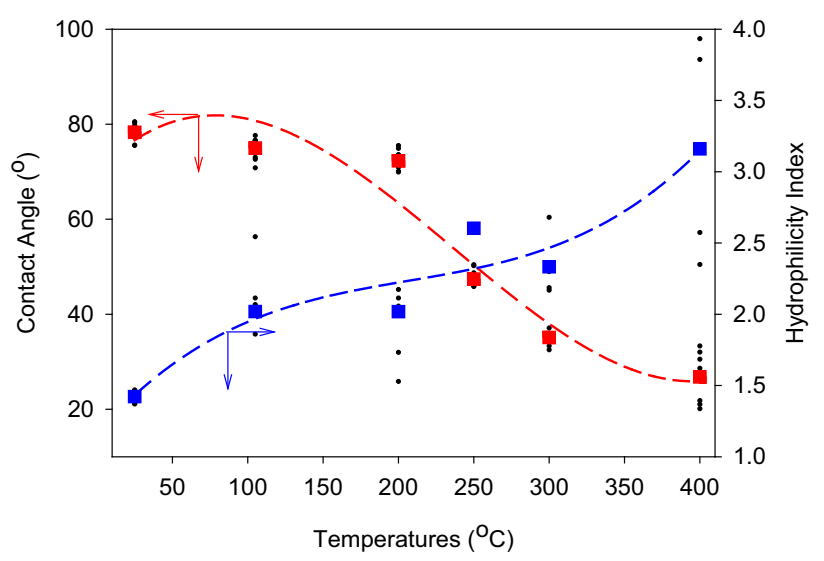

Fig. 8 Contact angles and the hydrophilicity index as a function of oxidation treated temperature

$$
\begin{aligned}
\text { Hydrophilicity Index }= & (-\mathrm{COOH})+2(-\mathrm{OH}) /(\mathrm{RH}) \\
& +(\mathrm{Ar}-\mathrm{H})
\end{aligned}
$$

where $(-\mathrm{COOH}),(-\mathrm{OH}),(\mathrm{RH})$ and $(\mathrm{Ar}-\mathrm{H})$ are the values of the absorption intensity obtained using FTIR and diffuse reflectance technique. These results of hydrophilicity index defined by Yordan and Yoon (1988) corresponded very well to the correlation with directly measured contact angles as shown in Fig. 8. The increase in the number of polar groups on the coal surface was expected to cause the coal to become more hydrophilic. Consequently, the hydrophilicity index increased with increasing oxidation of about 1.3 and 2.9. The increase in the hydrophilicity of the oxidized coals can be attributed to increased interfacial attractive forces between polar oxygenate functionality on the coal surface and liquid water (Gray et al. 1991). The concentration of hydrophobic functional groups on the coal surface decreased as the oxidation increased, while the concentration of hydrophilic groups increased. Adhesion force as a function of selected functional group and selected oxidation temperature is shown in Fig. 9. The ratio of the adhesion force for different functional groups can be predicted from their surface energy (Berger et al. 1995). The absorbance intensity of selected functional group corresponded to the adhesion force and higher ratio of

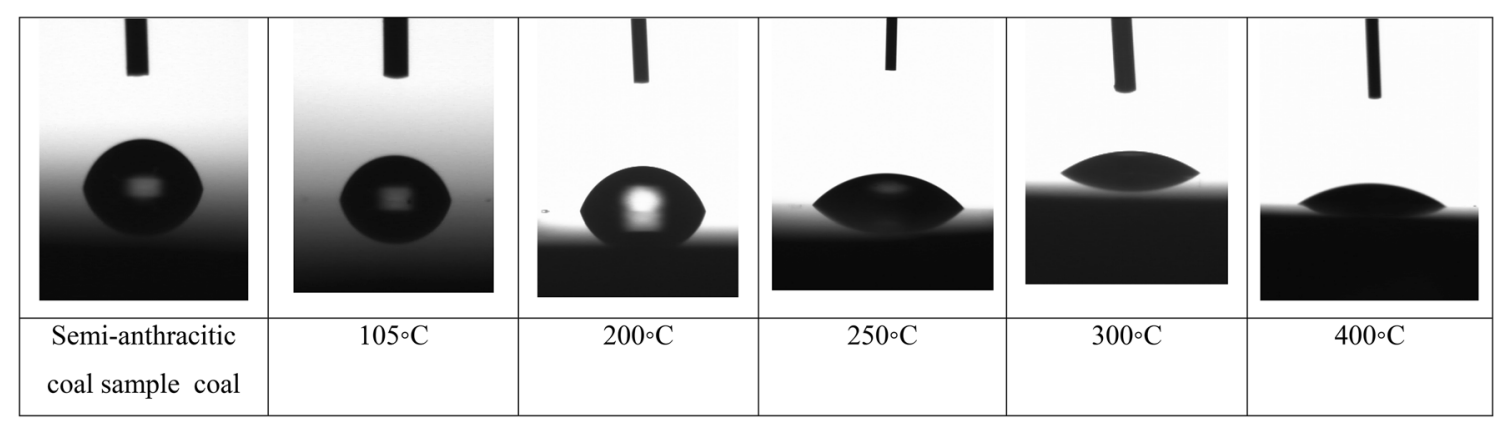

Fig. 7 Selected water sessile drop contact angles as a function of oxidation treated temperature measured on 10 spots for $10 \mathrm{~s}$ examination 


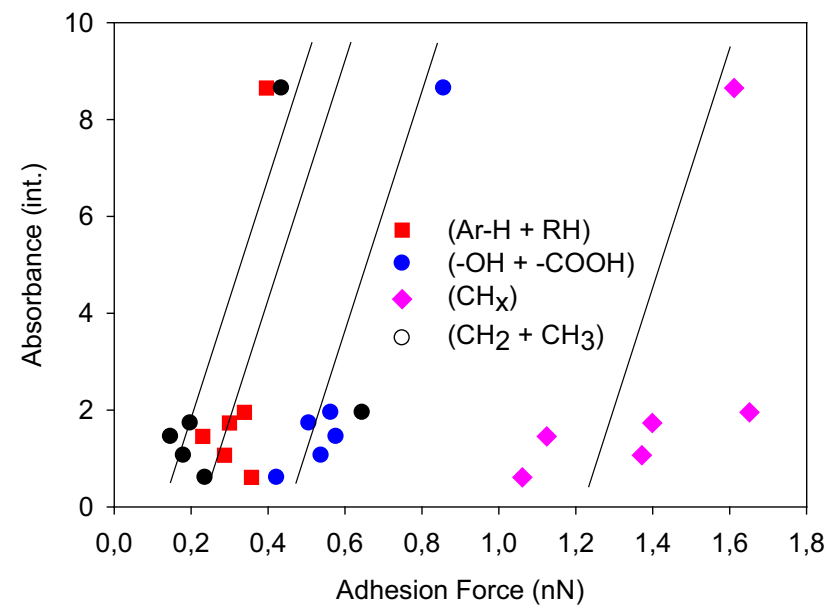

Fig. 9 Adhesion force as a function of selected functional group and oxidation treated temperature

polar group increased the adhesion force. These results from macroscopic observations of contact angles were also done by the microscopic AFM observation, confirming that under oxidizing conditions the coal surfaces were rendered more hydrophilic due to the coverage by the oxygen complexes.

\subsection{TG-DTA examination results}

The DTAs and DTGs curves of the semi-anthracitic coal sample and oxidized coal products and its combustion characteristic are shown in Figs. 10 and 11. It is noted that by increasing the oxidation temperature not only increased the DTG peak intensity, but also accelerated the peak to lower temperatures, indicating a gradual change in the loss of mass and a change coal surface structure. The loss of coal organic matter during air combustion of oxidized coal was faster than of semi-anthracitic coal, which was likely associated with the coal matrix via oxygen functional groups, appeared to be mainly affected by the air combustion DTG at temperatures lower than $600{ }^{\circ} \mathrm{C}$.

The ignition temperature $\left(T_{\mathrm{ig}}\right)$ is an important characteristic of coal combustion, especially for low rank coal, due to its high intensity of spontaneous combustion (Mahidin et al. 2003). The ignition temperature is taken as the extrapolated onset temperature of the first peak of the DTA curve, which also corresponds to the temperature at which the TG curve departs from the baseline. The ignition temperature in this study corresponded to the $T_{\mathrm{ig}}$ of the volatile matter. The curves illustrate the heat differentiation that occurred during the analysis. The DTA peak appeared at around 561.5 to $571{ }^{\circ} \mathrm{C}$ (exothermic) represents the combustion of char (Ma et al. 1989). The shifting of the DTA peaks of the oxidized products at lower temperature demonstrated that significant heat release had occurred
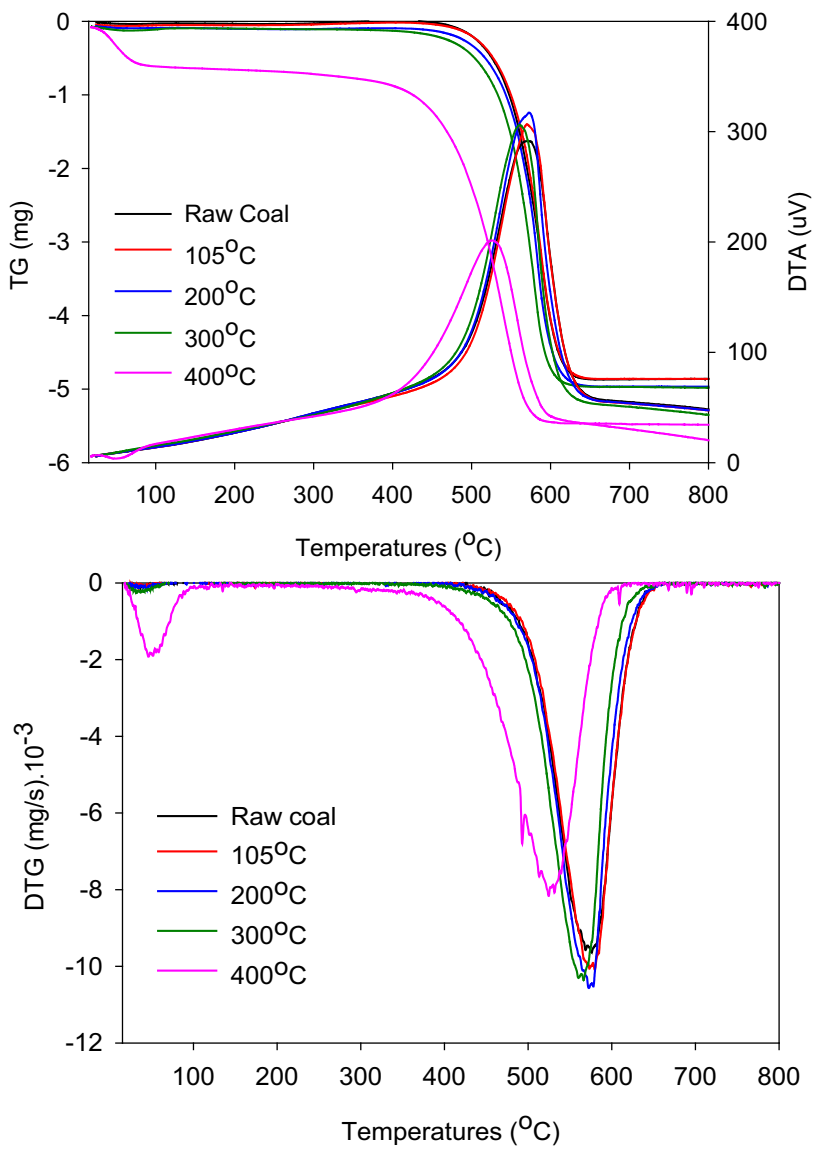

Fig. 10 TG, DTA and DTG profile of a semi-anthracitic coal sample and oxidized coal as a function of oxidation treated temperature

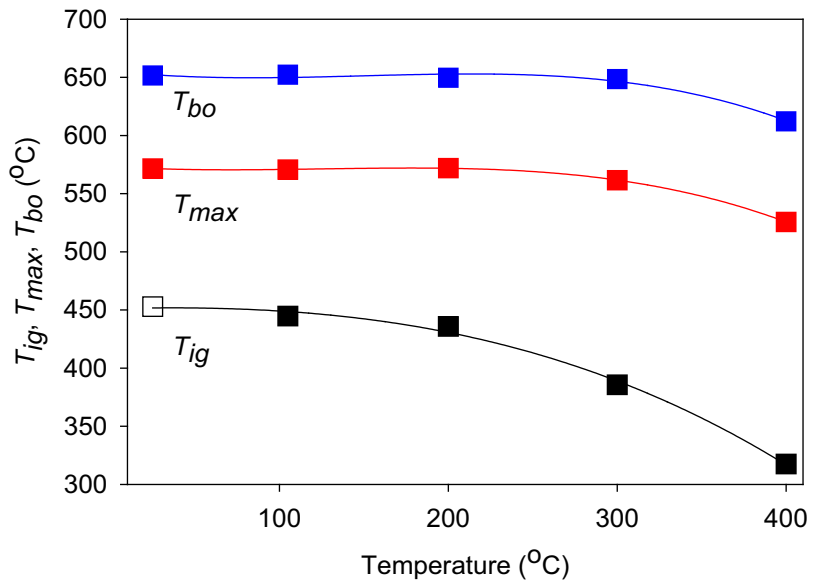

Fig. $11 T_{i g}, T_{\max }$ and $T_{b o}$ profile of a semi-anthracitic coal sample and oxidized coal as a function of oxidation treated temperature

during the combustion of coal. Based on this fact, the calorific value of the peat fuel products likely decreased as the oxidizing temperature increased.

Figure 10 shows the effect of temperature on combustion parameters based on the DTA-TG analysis. The $T_{\mathrm{ig}}$ of semi-anthracitic coal sample and oxidized coal was 
$452.9^{\circ} \mathrm{C}$ and between 444.7 and $385.7{ }^{\circ} \mathrm{C}$, respectively. The $T_{\text {ig }}$ of all oxidized coal progressively decreased as the temperature increased when compared to the $T_{\text {ig }}$ of semianthracitic coal. The decrease in $T_{\mathrm{ig}}$ was ascribed to the increase in the volatile matter in oxidized coal. Therefore, it is apparent to cite a general comparison between semianthracitic coal sample and oxidized coal because the reactivity of oxygen primarily influenced their ignition and ascribed to the increase in the oxygen content of oxidized coal. Oxidized coal had a lower ignition temperature and relatively higher mass loss in the low temperature range, indicating that it was easy to ignite and burn out. Therefore, the liability or susceptibility to spontaneous combustion of oxidized coal was higher when compared to the semi-anthracitic coal.

The temperature at the maximum combustion rate $\left(T_{\max }\right)$ is related to the coal reactivity, and reactive coal has a lower $T_{\max }$. As shown in Fig. 10, $T_{\max }$ relatively decreased as the temperature increased when compared to semi-anthracitic coal. The $T_{\max }$ of the semi-anthracitic coal sample and oxidized coal was observed at $571.6^{\circ} \mathrm{C}$ and between 570.7 and $561.5^{\circ} \mathrm{C}$, suggesting that the reactivity of the oxidized coal decreased. The $T_{\mathrm{bo}}$ of the oxidized coal, which reflected their char characteristics, ranged from 652.3 to $648.5^{\circ} \mathrm{C}$. Conversely, the $T_{\max }$ of all oxidized coal, which indicates the maximum combustion rate, was much lower than that of the semi-anthracitic coal. These findings suggest that it could be potentially easier for the high-quality coal to be oxidized due to the future application of inappropriate coal blending method with low rank coal which has high susceptibility to spontaneous combustion.

\section{Conclusion}

The effects of air oxidation treatment on physicochemical properties of coal surface present in several interesting phenomena on adhesion force and hydrophobicity properties. Data from the current study indicate that as the oxidation temperature increased, the hydrophobicity of coal decreased, which in turn increased the adhesion force value. The coverage of oxygen complexes was also affected by the decreasing of contact angle and least resistance to the hygroscopic properties. An indication of lowering ignition temperature of oxidized coal was mainly influenced by the reactivity of oxygen and ascribed to the increase in the oxygen content of oxidized coal.

It was found that significant changes occurred in the oxygen content of the functional groups. The aliphatic hydrocarbons decomposed most readily into unstable aliphatic hydrocarbon and produced carbonyl groups. The increase in oxidation temperature showed the gradual generation of carboxyl groups. Aromatic nuclei $\mathrm{CH}$ was the most diminished in its relative intensity at temperature of $400{ }^{\circ} \mathrm{C}$. There was also a significant correlation between the development of $\mathrm{C}=\mathrm{O}$ and $\mathrm{COOH}$ and $\mathrm{C}-\mathrm{O}-\mathrm{R}$ structures of ethers during the oxidation process.

Acknowledgements The authors express appreciation for the support of this research by the Indonesian Institute of Sciences (LIPI) - Excellent Research Program-Materials Development, Energy and Manufacture Engineering (KU-PMERM). The authors also acknowledge the support from the Mineral Processing, Recycling and Environment Remediation Laboratory; Research and Education Center of Carbon Resources-Kyushu University. Financial aid was partly provided by a KU-PMERM and Core Competence Research Program-Research Centre for Geotechnology_LIPI 2015-2017.

Open Access This article is distributed under the terms of the Creative Commons Attribution 4.0 International License (http://crea tivecommons.org/licenses/by/4.0/), which permits unrestricted use, distribution, and reproduction in any medium, provided you give appropriate credit to the original author(s) and the source, provide a link to the Creative Commons license, and indicate if changes were made.

\section{References}

Apian FF (1983) Examining the floatability of western coals. geology, mining, extraction and the environment. AIME, New York, p 380

Berger CEH, van der Werf KO, Kooyman RPH, de Grooth BG, Greve J (1995) Functional group imaging by adhesion AFM applied to lipid monolayers. Langmuir 11(11):4188-4192

Bouwman R, Freriks ILC (1980) Low temperature oxidation of a bituminous coal. infrared spectroscopic study of samples from a coal pile. Fuel 59:315-322

Brady GA, Gauger AW (1940) Properties of coal surfaces. Ind Eng Chem 32:1599

Bruening FA, Cohen AD (2005) Measuring surface properties and oxidation of coal macerals using atomic force microscope. Int $\mathrm{J}$ Coal Geol 63:195-204

Butt HJ, Cappella B, Kappl M (2005) Force measurements with the atomic force microscope: technique, interpretation, and applications. Surf Sci Rep 59:1-152

Clemens AH, Matheson TW, Rogers DE (1990) DTA studies of the low temperature oxidation of low rank coals. Fuel 69:255-256

Cohen AD, Bailey AM, Myrick ML, Doescher M, Friese WC (1998) Applications of atomic force microscopy to study of artificially coalified peats. Soc Org Petrol 15:23-27

Das T, Becker T, Nair BN (2010) Measurements on hydrophobic and hydrophilic surfaces using a porous gamma alumina nanoparticle aggregate mounted on atomic force microscopy cantilevers. Thin Solid Films 518:2769-2774

Datta A, Nalaskowski J, Paruchuri VK, Miller JD (2000) Interaction forces between a coal surface and a polystyrene sphere in the presence of cationic and anionic surfactants as measured using atomic force microscopy. Coal Prep 21:337-353

Drelich J, Laskowski JS, Pawlik M, Veeramasuneni S (1997) Preparation of a coal surface for contact angle measurements. J Adhes Sci Technol 11(11):1399-1431

Farquhar ML, Wincott PL, Wogelius RA, Vaughan DJ (2003) Electrochemical oxidation of the chalcopyrite surface: an XPS and AFM study in solution at pH 4. Appl Surf Sci 218:34-43 
Fuji M, Machida K, Takei T, Watanabe T, Chikazawa M (1999) Effect of wettability on adhesion force between silica particles evaluated by atomic force microscopy measurement as a function of relative humidity. Langmuir 15:4584-4589

Gethner JS (1985) Thermal and oxidation chemistry of coal at low temperatures. Fuel 64:1443-1446

Gethner JS (1987) The mechanism of the low-temperature oxidation of coal by $\mathrm{O}_{2}$ : observation and separation of simultaneous reactions using in situ FT-IR difference spectroscopy. Appl Spectrosc 41(1):50-63

Gray ML, Lai RW, Wells AW (1991) Surface modification of oxidized coal by methanol vapor. U.S. Dept. of Energy, Pittsburgh, pp 804-813

Horsley RM, Smith HG (1951) Principles of coal flotation. Fuel 30:54-63

Huffman GP, Huggins FE, Dunmyre GR, Pignocco AJ, Lin MC (1985) Comparative sensitivity of various analytical techniques to the low-temperature oxidation of coal. Fuel 64:849-856

Jones R, Pollock HM, Cleaver JAS, Hodges CS (2002) Adhesion forces between glass and silicon surfaces in air studied by AFM: effect of relative humidity, particle size, roughness, and surface treatment. Langmuir 18:8045-8055

Karoussi O, Skovbjerg L, Hassenkam T, Svane Stipp SL, Hamouda AL (2000) AFM study of calcite surface exposed to stearic and heptanoic acids. Colloids Surf A 325:107-114

Lawrie GA, Gentle IR, Fong C, Glickson M (1997) Atomic force microscopic studies of Bowen Basin coal macerals. Fuel 76:1519-1526

Leite FL, Riul AJR, Herrmann PSP (2003) Mapping of adhesion forces on soil minerals in air and water by atomic force spectroscopy (AFS). J Adhes Sci Technol 17:2141-2156

Liang Y, Tian F, Luo H, Tang H (2015) Characteristics of coal reoxidation based on microstructural and spectral conservation. Int J Min Sci Technol 25(5):749-754

Liotta R, Brons G, Isaacs J (1983) Oxidative weathering of Illinois No. 6 coal. Fuel 62:781-791

Liu J, Jiang X, Huang X, Wua S (2010) Morphological characterization of superfine pulverized coal particle. Part2. AFM investigation of single coal particle. Fuel 89:3884-3891

Ma S, Hill JO, Heng S (1989) A thermal analysis study of the combustion characteristics of Victorian brown coals. J Therm Anal 35:1985-1996

Mahidin, Ogaki J, Usui H, Okuma O (2003) The advantages of vacuum treatment in the thermal upgrading of low-rank coals on the improvement of dewatering and devolatilization. Fuel Process Technol 84:147-160

Matyjaszczyk MS, Przeliorz R (1985) Thermochemistry of coal oxidation. Thermochim Acta 96(1):169-187

Morga R (2011) Changes of semifusinite and fusinite surface roughness during heat treatment determined by atomic force microscopy. Int J Coal Geol 88:218-226

Mursito AT, Hirajima T (2012) Hydrothermal treatment of hokkaido peat; An application of FTIR and 13C NMR spectroscopy on examining of artificial coalification process and development. In: Theophanides Theophile (ed) Infrared spectroscopy-materials science, engineering and technology. InTech, Rijeka, pp 179-192

Mursito AT, Hirajima T, Sasaki K (2010) Upgrading and dewatering of raw tropical peat by hydrothermal treatment. Fuel 89:635-641
Mursito AT, Hirajima T, Sasaki K (2011) Alkaline hydrothermal deashing and desulfurization of low quality coal and its application to hydrogen-rich gas generation. Energ Convers Manag 52:762-769

O'Brien WJ, Hermann JJ (1973) The strength of liquid bridges between dissimilar materials. J Adhes Sci Technol 5:91-103

Ohki A, Xiao FX, Nakajima T, Itahara T, Maeda S (1999) Change in property and combustion characteristics of an Indonesian coal due to hydrothermal treatment. Coal Prep 21:23-24

Ozdemir O, Taran E, Hampton MA, Karakashev SI, Nguyen AV (2009) Surface chemistry aspects of coal flotation in bore water. Int J Miner Process 92:177-183

Pan J, Zhu H, Hou Q, Wanga H, Wang S (2015) Macromolecular and pore structures of Chinese tectonically deformed coal studied by atomic force microscopy. Fuel 139:94-101

Petrus HTBM, Hirajima T, Sasaki K, Okamoto H (2011) Effect of pH and diethyl dithiophosphate (DTP) treatment on chalcopyrite and tennantite surfaces observed using atomic force microscopy (AFM). Colloids Surf A 389:266-273

Rhoads CA, Senftle JT, Coleman MM, Davis A, Painter PC (1983) Further studies of coal oxidation. Fuel 62:1387-1392

Rosidi HMD, Tjokrosapoetro S, Pendowo B, Suharsono S (1996) Geology map of the Painan Quadrangle, Sumatra, scale 1: 250000. Report Geological Research and Development Centre, Bandung

Sedin DL, Rowlen KL (2000) Adhesion forces measured by atomic force microscopy in humid air. Anal Chem 72:2183-2189

Sun SC (1954) Hypothesis for different floatabilities of coals, carbons, and hydrocarbon minerals. Trans AIME 199:67-75

Tahmasebi A, Yu J, Han Y (2012) Study of chemical structure changes of chinese lignite upon drying in superheated steam, microwave and hot air. Energy Fuels 26(6):3651-3660

Umar DF, Daulay B, Usui H, Deguchi T, Sugita S (2005) Characterization of upgraded brown coal (UBC). Coal Prep 25:31-45

Wang D, Zhong X, Junjie GU, Xuyao QI (2010) Changes in active functional groups during low-temperature oxidation of coal. Min Sci Technol 20:35-40

Wu D, Liu GJ, Sun RY, Chen SC (2014) Influences of magmatic intrusion on the macromolecular and pore structures of coal: evidences from Raman spectroscopy and atomic force microscopy. Fuel 119:191-201

Xia W, Xie G (2014) Changes in the hydrophobicity of anthracite coals before and after high temperature heating process. Powder Technol 264:31-35

Xia W, Yang J (2014) Changes in surface properties of anthracite coal before and after inside/outside weathering processes. Appl Surf Sci 313:320-324

Yordan JL, Yoon RH (1988) Induction time measurements for a coal flotation systems. In: Attia YA, Moudgil BM, Chander S (eds) Interfacial phenomena in biotechnology and materials processing. Elsevier, Amsterdam, pp 333-334

Yumura M, Ohshima S, Kuriki Y, Ikazaki F, Suzuki Y (1993) Atomic force microscopy observations of coals. In: Proceedings of international conference on coal science 1. NIMC, Tsukuba, pp 394-397

Yürüm Y, Altuntas N (1998) Air oxidation of Beypazari lignite at $50^{\circ} \mathrm{C}, 100^{\circ} \mathrm{C}$ and $150^{\circ} \mathrm{C}$. Fuel $77: 1809-1814$ 